\title{
Block copolymer-mediated synthesis of silver nanoparticles from silver ions in aqueous media
}

Toshio Sakai $^{1) *}$, Akihiro Ishihara $^{1)}$ and Paschalis Alexandridis ${ }^{2)}$

1) Department of Chemistry and Material Engineering, Faculty of Engineering, Shinshu University, 4-17-1 Wakasato, Nagano 380-8553, Japan

2) Department of Chemical and Biological Engineering, University at Buffalo, The State University of New York, Buffalo, NY 14260-4200

* To whom correspondence should be addressed.

phone : +81-26-269-5405

fax : +81-26-269-5424

e-mail : tsakai@ shinshu-u.ac.jp 


\begin{abstract}
We report here on the silver (Ag) nanoparticle synthesis in aqueous solutions of poly(ethylene oxide)-poly(propylene oxide) (PEO-PPO) block copolymers in the absence of any additional agents. In particular, we examined the effect of reaction temperature, molecular weight of PEO-PPO block copolymer and PEO-PPO block copolymer concentration on the reduction of silver ions $\left(\mathrm{Ag}^{+}\right)$and the resulting formation of $\mathrm{Ag}$ nanoparticles in aqueous PEO-PPO block copolymer solutions. We found that Ag nanoparticles were formed from aqueous silver nitrate $\left(\mathrm{AgNO}_{3}\right)$ solutions containing PEO-PPO block copolymer above $100^{\circ} \mathrm{C}$. This is most likely due to the dehydration of $\mathrm{Ag}^{+}$caused by thermal motion of water molecules in higher-temperature aqueous solution at high vapor pressure. We also found that the formation of Ag nanoparticles in aqueous PEO-PPO block copolymers with larger molecular weight and with increase in the concentration of PEO-PPO block copolymer in aqueous solutions.
\end{abstract}

Keywords: Silver nanoparticle, Poly(ethylene oxide)-poly(propylene oxide) block copolymer, Silver nitrate, Silver ion reduction, Reaction temperature, Hydration, Dehydration. 


\section{Introduction}

Nanometer-sized metal particles (metal nanoparticles) are attracting significant attention in the last couple of decades because of their unique properties that are distinct from bulk metal and their wide applications in chemistry, physics and biology fields [1-21]. The physical and chemical properties of metal nanoparticles depend strongly on the size, shape and assembly of metal nanoparticles. Therefore, it is still important and challenging task to develop the controllable synthesis of metal nanoparticles with different sizes, shapes and assemblies. There are a number of reports on the controlling size and shape of metal nanoparticles in wet chemistry. For examine, the size, shape and assembly of gold nanoparticles are controlled by judicious combination of the capping agents (e.g., alkylthiols, surfactants and polymers) and reducing agents (e.g., $\mathrm{NaBH}_{4}$, hydrazine and ascorbic acid). Furthermore, the block copolymer- and supramolecule-mediated synthesis of gold nanoparticles has been developed because the block copolymers and supramolecules can display dual function: the reducing function for metal ions and capping (stabilizing) function for metal nanoparticles formed [22-32]. Silver (Ag) nanoparticles are synthesized through the citrate reduction, silver mirror reaction, polyol process, seed-mediated growth and light-mediated synthesis [19]. We have also developed a facile and efficient synthetic method of gold and silver nanoparticles from reduction of tetrachloroaureate(III) ions $\left(\left[\mathrm{AuCl}_{4}\right]^{-}\right)$and silver ions $\left(\mathrm{Ag}^{+}\right)$in solutions of poly(ethylene oxide)-poly(propylene oxide) (PEO-PPO) block copolymers, respectively (named as block copolymer-mediated synthetic method) [33-42]. In this method, gold nanoparticles are formed in both aqueous and formamide solutions of PEO-PPO block copolymers in the temperature range of 4-100 ${ }^{\circ} \mathrm{C}$. On the other hand, $\mathrm{Ag}$ nanoparticles are formed from silver nitrate $\left(\mathrm{AgNO}_{3}\right)$ formamide solutions of PEO-PPO block copolymer at $100{ }^{\circ} \mathrm{C}$ but not from aqueous $\mathrm{AgNO}_{3}$ solutions of PEO-PPO block copolymers at $100{ }^{\circ} \mathrm{C}$ for $24 \mathrm{~h}[37,38]$. Then, we explore the 
synthesis of $\mathrm{Ag}$ nanoparticles directly from aqueous $\mathrm{AgNO}_{3}$ solutions of PEO-PPO block copolymers in the absence of any additional agents. The development of synthetic methodology of other metal nanoparticles from gold nanoparticles in aqueous media should provide further opportunities of the block copolymer-mediated synthesis of metal nanoparticles.

In the present work, we examine the effect of reaction temperature, molecular weight of PEO-PPO block copolymer and PEO-PPO block copolymer concentration on the reduction of silver ions $\left(\mathrm{Ag}^{+}\right)$and the resulting formation of $\mathrm{Ag}$ nanoparticles in aqueous solutions of PEO-PPO block copolymers. Different from other studies on the Ag nanoparticle synthesis using PEO-PPO block copolymers[43-49], the methodology that we present here aims at the direct synthesis of $\mathrm{Ag}$ nanoparticles from $\mathrm{Ag}^{+}$in aqueous PEO-PPO block copolymer solutions in the absence of any additives but not from $\left[\mathrm{Ag}\left(\mathrm{NH}_{3}\right)_{2}\right]^{+}[43-45]$, not in the lyotropic liquid crystal phase (that is formed in high concentration of PEO-PPO block copolymers) [46] and not in the presence of additives such as reducing agents [47-49].

\section{Experimental}

\subsection{Ag Nanoparticle Synthesis}

Silver (Ag) nanoparticles were prepared by mixing a $20 \times 10^{-3} \mathrm{~mol} \mathrm{~L}^{-1}$ silver nitrate $\left(\mathrm{AgNO}_{3} ; 99.999+\%\right.$, Aldrich) aqueous (18.2 $\mathrm{M} \Omega \mathrm{cm}$, Millipore-filtered water) solution (0.25 $\mathrm{mL}$ ) with aqueous solutions ( $25 \mathrm{~mL})$ containing poly(ethylene oxide)-poly(propylene oxide) (PEO-PPO) block copolymer $\left(\mathrm{H}\left(\mathrm{OCH}_{2} \mathrm{CH}_{2}\right)_{x}\left(\mathrm{OCH}_{2}\left(\mathrm{CH}_{3}\right) \mathrm{CH}\right)_{y}\left(\mathrm{OCH}_{2} \mathrm{CH}_{2}\right)_{x} \mathrm{OH}\right.$; Pluronic, BASF Corp.) or poly(ethylene oxide) (PEO) homopolymer $\left(\mathrm{H}\left(\mathrm{OCH}_{2} \mathrm{CH}_{2}\right)_{x} \mathrm{OH}\right.$; Sigma-Aldrich) in 50 $\mathrm{mL}$ container of a Teflon-lined stainless steel autoclave. The PEO-PPO block copolymers that we considered for Ag nanoparticle synthesis in this work are Pluronic P103, Pluronic F68, Pluronic F88, Pluronic F127 and Pluronic F108 [34]. For comparison purposes, a PEO 
homopolymer (PEG8000, Sigma-Aldrich) was applied for Ag nanoparticle synthesis. Properties of the PEO-PPO block copolymers and a PEO homopolymer considered here are listed in Table 1. The various polymers allow us to examine the effects of metal ion reduction activity (due to block copolymer overall chain length and/or PEO block length) and polymer adsorption, colloidal stabilization (due to block copolymer overall chain length and hydrophobicity) and presence of block copolymer micelles on the formation and structure of $\mathrm{Ag}$ nanoparticles. The $\mathrm{Ag}^{+}$concentration following mixing (at the start of the reaction) was $2.0 \mathrm{x}$ $10^{-4} \mathrm{~mol} \mathrm{~L}^{-1}$. The polymer concentrations reported here are those of the polymer solution prior to mixing with the metal ion solution (the polymer concentration in the reaction medium was $1.0 \%$ lower than that before mixing). In order to examine the effect of reaction temperature on Ag nanoparticle formation, following agitation by vortex mixer for $\sim 10 \mathrm{sec}$, the solutions were left standing in temperature range of $5-140{ }^{\circ} \mathrm{C}$ for $24 \mathrm{~h}$ in $50 \mathrm{~mL}$ container of a Teflon-lined stainless steel autoclave for the reaction to be completed. For comparison purposes, diamminesilver(I) ions $\left(\left[\mathrm{Ag}\left(\mathrm{NH}_{3}\right)_{2}\right]^{+}\right)$was tested as a silver precursor for $\mathrm{Ag}$ nanoparticle synthesis in aqueous PEO-PPO block copolymer solutions in temperature range of $5-140{ }^{\circ} \mathrm{C}$ for $24 \mathrm{~h}$.

\subsection{Characterization}

The formation of Ag nanoparticles was monitored by observing changes in the absorption spectra centered at $\sim 410 \mathrm{~nm}$ originating from the Surface Plasmon Resonance (SPR) of Ag nanoparticles [50] using a UV-visible spectrophotometer (V-630, JASCO Corporation) at room temperature. The size and shape of the obtained Ag nanoparticles were determined by a transmission electron microscope (TEM) (JEM-2010, JEOL Ltd.) in conventional transmission mode using $200 \mathrm{kV}$. The preparation of the TEM samples involved several steps of dilution with water and concentration via centrifugation in order to remove excess block copolymer. 
Formation of Ag nanoparticles was also confirmed from X-ray diffraction pattern measured with powder X-ray diffraction (XRD) system (RINT-2200V PC, RIGAKU).

\section{Proposed Mechanism on Silver Ion Reduction by PEO-PPO Block Copolymers in Aqueous}

\section{Solutions}

In order to achieve the direct synthesis of $\mathrm{Ag}$ nanoparticles from reduction of $\mathrm{Ag}^{+}$by PEO-PPO block copolymers in aqueous solutions, we first consider the mechanism of $\mathrm{Ag}^{+}$ reduction by PEO-PPO block copolymers. On the basis of information reported for the reduction of metal ions by PEO-type surfactants $[1,2]$, PEO homopolymer $[51,52]$ and PEO-containing polymers [22-24] and our previous work [33-42], three possible mechanisms of metal ion reduction by PEO-PPO block copolymers are proposed as described below ( $\mathrm{a}, \mathrm{b}$ and $\mathrm{c}$ ). We believe that the mechanism (c) is the most responsible for metal ion reduction in PEO-PPO block copolymer systems.

(a) Alcohol (hydroxyl) functionality of a PEO-PPO block copolymer molecule for metal ion reduction $[1,3]$.

Alcohols are very often used as reducing agents for the synthesis of metal nanoparticles $[1,3$, 19]. However, in our experiments, the reduction of $\mathrm{Ag}^{+}$ions and $\mathrm{Ag}$ nanoparticle formation are not observed in aqueous solutions containing alcohols (e.g., methanol, ethanol, 1-propanol, 2-propanol, ethylene glycol and glycerol) at concentrations that are consistent with the PEO-PPO block copolymer concentration range used in our work.

(b) Oxidizing and reducing function of hydroperoxides $(\mathrm{ROCOOH})$ formed from polyethers such as PEO-PPO block copolymers upon reaction with oxygen from the air [1, 2, 24]

It is reported that the hydroperoxides formed from oxidation of the surfactant most likely were responsible for metal ion reduction. We tested the formation of $\mathrm{Ag}$ nanoparticles with 
PEO-PPO block copolymers (e.g., $\mathrm{EO}_{6} \mathrm{PO}_{22} \mathrm{EO}_{6}$, Pluronic L44) having PEO block length comparable to that of the reported PEO-type surfactants [1,2], and found that $\mathrm{Ag}^{+}$reduction and Ag nanoparticle formation were not observed. So, this effect is significantly small even if PEO-PPO block copolymers were forming hydroperoxides in air-saturated water. If hydroperoxides formed from PEO-PPO block copolymers facilitate metal ion reduction, the effect of PEO block length does not need to be considered because oxidation of polyether occurs only at endgroup of polymer. Namely, the formation of hydroperoxides cannot explain the effects of block copolymer molecular weight (block length).

(c) Reduction of bound $\mathrm{Ag}^{+}$ions with cavities (pseudocrown ether structure) [53-61] through oxidation of the oxyethylene and oxypropylene segments by the metal center [51].

Poly(ethylene oxide) (PEO) forms a conformation similar to crown ethers (pseudocrown ether structure) by binding with metal ions in aqueous solution due to the ion-dipole interactions between the metal ions and the electron lone pairs of the ethylene oxide linkages [53-56]. The cyclization of PEO with metal ions requires longer (> $\left.\mathrm{EO}_{7}\right)$ PEO chains $[53,54]$. The strength of the attraction is afforded by the interaction of several oxygen atoms in the PEO chain with one ion $[53,54,59]$. This mechanism can explain the effect of PEO chain length on the metal ion reduction. This mechanism can explain reasonably our experimental results; in particular, effects of block copolymer block length (molecular weight) so that we believe that this process primary works for metal ion reduction in PEO-PPO block copolymer systems.

\section{Results and Discussion}

\subsection{Ag Nanoparticle Formation in Aqueous PEO-PPO Block Copolymer Solutions}

Silver $(\mathrm{Ag})$ nanoparticles are formed from silver nitrate $\left(\mathrm{AgNO}_{3}\right)$ formamide solutions of PEO-PPO block copolymers at $100{ }^{\circ} \mathrm{C}$ but not from aqueous solutions at $100{ }^{\circ} \mathrm{C}$ (the reaction 
period for $24 \mathrm{~h}$ ) [37, 38]. Indeed, we confirmed that no remarkable absorption band originating from SPR of Ag nanoparticles was observed in every aqueous solution of PEO-PPO block copolymers that we examined in this work in the temperature range of $5-100{ }^{\circ} \mathrm{C}$ (see Figure 1). This indicates that Ag nanoparticles were not formed in aqueous PEO-PPO block copolymer solutions in the temperature range of $5-100{ }^{\circ} \mathrm{C}$. Then, we tested the Ag nanoparticle synthesis above $100{ }^{\circ} \mathrm{C}$ in $10 \mathrm{wt} \%$ PEO-PPO block copolymer aqueous solutions. In the temperature at 120 and $140{ }^{\circ} \mathrm{C}$, the absorption band centered at $\sim 410 \mathrm{~nm}$ originating from SPR of $\mathrm{Ag}$ nanoparticles was observed in aqueous solutions of Pluronic F88, Pluronic F127 and Pluronic F108 but not in aqueous solutions of Pluronic F68 and Pluronic P103 (see Figure 1 and upper panel of Figure 2). This indicates that Ag nanoparticles were formed in aqueous Pluronic F88, Pluronic F127 and Pluronic F108 solutions at 120 and $140{ }^{\circ} \mathrm{C}$ but not in aqueous Pluronic F68 and Pluronic P103 solutions. TEM observation revealed the formation of spherical, plate-like and rod-like Ag nanoparticles at $120{ }^{\circ} \mathrm{C}$ in aqueous solutions of Pluronic F88, Pluronic F127 and Pluronic F108 (see Figure 3). The X-ray diffraction measurement confirmed the formation of Ag nanoparticles but not $\mathrm{Ag}_{2} \mathrm{O}$ nanoparticles (see Figure 4). The peaks observed in XRD patterns shown in Figure 4 are assigned to (111), (200), (220) and (311) facets of silver. Note here that $\mathrm{Ag}$ nanoparticles were not formed from aqueous $\mathrm{AgNO}_{3}$ solution in the absence of PEO-PPO block copolymers even after heating at 120 and $140{ }^{\circ} \mathrm{C}$ for $24 \mathrm{~h}$. No noticeable absorption band was observed in aqueous $\mathrm{AgNO}_{3}$ solution after heating at 120 and $140{ }^{\circ} \mathrm{C}$ for 24 h (see bottom panel of Figure 1 and upper panel of Figure 5). This indicates that the reduction of $\mathrm{Ag}^{+}$in aqueous PEO-PPO block copolymer solutions above $100{ }^{\circ} \mathrm{C}$ is not caused by hydrothermal reaction due to the high-temperature aqueous solutions at higher vapor pressure. We also revealed that the increase in the polymer concentration promoted the $\mathrm{Ag}^{+}$reduction and Ag nanoparticle formation. Absorbance centered at $\sim 410 \mathrm{~nm}$ originating from SPR of Ag 
nanoparticles increased with increasing the polymer concentration (see Figure 5). These results support that the $\mathrm{Ag}^{+}$reduction in aqueous solutions is attributed to the reducing function of PEO-PPO block copolymers. Furthermore, we confirmed that Ag nanoparticles were not formed by mixing of an aqueous $\mathrm{AgNO}_{3}$ solution with a hydrothermal-treated aqueous solution of PEO-PPO block copolymer (the result is not presented here).

\subsection{Connection between Reaction Temperature and Ag Nanoparticle Formation in Aqueous PEO-PPO Block Copolymer Solutions}

Now we realized that the formation of Ag nanoparticles in aqueous PEO-PPO block copolymer solutions required higher temperature than $100{ }^{\circ} \mathrm{C}$. So, let us consider here the mechanism on the formation of $\mathrm{Ag}$ nanoparticles from $\mathrm{Ag}^{+}$above $100{ }^{\circ} \mathrm{C}$ in aqueous PEO-PPO block copolymer solutions by comparison between $\left[\mathrm{Ag}\left(\mathrm{NH}_{3}\right)_{2}\right]^{+}$and $\mathrm{Ag}^{+}$as silver precursor ions. In the case of $\mathrm{Ag}$ nanoparticle synthesis from $\left[\mathrm{Ag}\left(\mathrm{NH}_{3}\right)_{2}\right]^{+}$in aqueous PEO-PPO block copolymer solutions, Ag nanoparticles are formed at ambient temperature [43-45]. We also confirmed the $\mathrm{Ag}$ nanoparticle formation from $\left[\mathrm{Ag}\left(\mathrm{NH}_{3}\right)_{2}\right]^{+}$in aqueous PEO-PPO block copolymer solutions in the whole range of $5-140{ }^{\circ} \mathrm{C}$ in the absence of any additional agents. Typically, the magnitude of metal ion reduction is defined in terms of redox potential of metal ions. Namely, metal ions with higher redox potential should be reduced easily. However, in fact, $\mathrm{Ag}^{+}$with higher redox potential $\left(=0.799 \mathrm{~V}_{\mathrm{NHE}}\right.$ at $\left.25^{\circ} \mathrm{C}\right)$ than $\left[\mathrm{Ag}\left(\mathrm{NH}_{3}\right)_{2}\right]^{+}\left(=0.373 \mathrm{~V}_{\mathrm{NHE}}\right.$ at $25^{\circ} \mathrm{C}$ ) is not reduced in aqueous PEO-PPO block copolymer solutions at ambient temperature while $\left[\mathrm{Ag}\left(\mathrm{NH}_{3}\right)_{2}\right]^{+}$with lower redox potential than $\mathrm{Ag}^{+}$is easily reduced at ambient temperature in aqueous PEO-PPO block copolymer solutions. This suggests that the $\mathrm{Ag}^{+}$reduction and the resulting formation of Ag nanoparticles in aqueous PEO-PPO block copolymer solutions is not

related to the redox potential of silver precursor. Then, we consider that the $\mathrm{Ag}^{+}$reduction and 
the resulting formation of Ag nanoparticles in aqueous PEO-PPO block copolymer solutions are attributed to the hydration of $\mathrm{Ag}^{+}$in aqueous solutions. Namely, the hydration of $\mathrm{Ag}^{+}$by water molecules in aqueous solutions would prevent the interaction between $\mathrm{Ag}^{+}$and PEO-PPO block copolymers in aqueous solutions (see Figure 6). So, if the hydrated water molecules around $\mathrm{Ag}^{+}$were removed, $\mathrm{Ag}^{+}$could interact with PEO-PPO block copolymers directly, and $\mathrm{Ag}^{+}$ should be reduced by PEO-PPO block copolymers in aqueous solutions (see Figure 6). In general, smaller ions are more hydrated compared to larger ions. For example, $\mathrm{Ag}^{+}$is hydrated by 4 water molecules, while $\mathrm{Ag}\left(\mathrm{NH}_{3}\right)_{2}{ }^{+}$is hydrated by 2.8 water molecules because the size of $\mathrm{Ag}^{+}$is smaller than that of $\left[\mathrm{Ag}\left(\mathrm{NH}_{3}\right)_{2}\right]^{+}$. Thus, the incorporation of $\mathrm{Ag}^{+}$into the pseudo-crown ether structures of the PEO-PPO block copolymers would be prevented significantly due to the hydration compared with that of $\mathrm{Ag}\left(\mathrm{NH}_{3}\right)_{2}{ }^{+}$. Namely, the thermal motion of water molecules around $\mathrm{Ag}^{+}$enhanced by heating (above $100{ }^{\circ} \mathrm{C}$ ) would be required for removal of hydrated water from $\mathrm{Ag}^{+}$. We also considered another possible mechanism on the $\mathrm{Ag}$ nanoparticle formation in aqueous solutions above $100{ }^{\circ} \mathrm{C}$. Typically, the hydrothermal treatment with high temperature and high vapor pressure leads to the increase in the basicity of water. So, PEO-PPO block copolymers would be oxidized due to the increased basicity of water above 100 ${ }^{\circ} \mathrm{C}$, and consequently $\mathrm{Ag}^{+}$would be reduced to form $\mathrm{Ag}$ nanoparticles by the oxidation of PEO-PPO block copolymers. However, if the $\mathrm{Ag}^{+}$reduction by PEO-PPO block copolymers above $100{ }^{\circ} \mathrm{C}$ were promoted by the increased basicity of water by hydrothermal treatment, $\mathrm{Ag}$ nanoparticles must be formed in every PEO-PPO block copolymers and PEO homopolymer that we examined in this work at high temperature. Namely, molecular weight effect on the Ag nanoparticle formation from $\mathrm{Ag}^{+}$(as seen in Figure 2) should not be observed in PEO-PPO block copolymer system, if the increased basicity of water by hydrothermal treatment was main contributor to the Ag nanoparticle formation in PEO-PPO block copolymer system. Indeed, the 
formation of $\mathrm{Ag}$ nanoparticles from $\mathrm{Ag}\left(\mathrm{NH}_{3}\right)_{2}{ }^{+}$in PEO-PPO block copolymer system was independent on the molecular weight of PEO-PPO block copolymer and temperature. Thus, the $\mathrm{Ag}^{+}$reduction and $\mathrm{Ag}$ nanoparticle formation through the complexation $\mathrm{f}^{+} \mathrm{g}^{+}$with $\mathrm{PEO}-\mathrm{PPO}$ block copolymers above $100{ }^{\circ} \mathrm{C}$ would be attributed to the dehydration of water molecules from $\mathrm{Ag}^{+}$in the high-temperature aqueous solutions at higher vapor pressure.

\subsection{Connection between Molecular Weight of PEO-PPO Block Copolymer and Ag Nanoparticle Formation in Aqueous PEO-PPO Block Copolymer Solutions}

We also noticed that the absorbance centered at $\sim 410 \mathrm{~nm}$ originating from SPR of Ag nanoparticles plotted as a function of molecular weight of PEO-PPO block copolymer dramatically increased above $10,000 \mathrm{~g} \mathrm{~mol}^{-1}$ molecular weight of PEO-PPO block copolymer (see bottom panel of Figure 2). This means that Ag nanoparticle formation in aqueous PEO-PPO block copolymer solutions requires PEO-PPO block copolymers with higher molecular weight than $10,000 \mathrm{~g} \mathrm{~mol}^{-1}$. As described in section 3, the metal ion reduction by PEO-PPO block copolymers in aqueous solutions is caused by the formation of pseudocrown ether structures (cavities) with metal ions $[33,34,51,53-56]$. Reduction of bound metal ions proceeds via oxidation of the polymer by the metal center $[33,34,51]$. In particular, the level of hydration (swelling) and polymer loops of PEO-PPO block copolymers are related to the initial reduction process (complexation of PEO-PPO block copolymers with metal ions) [34]. Since longer chain (larger molecular weight) of PEO-PPO block copolymers provide a number of loop structures which act as reaction sites, $\mathrm{Ag}^{+}$would be reduced more significantly with longer chain (larger molecular weight) of PEO-PPO block copolymers.

4.4. Connection between Micelles Formation and Ag Nanoparticle Formation in Aqueous 


\section{PEO-PPO Block Copolymer Solutions}

Finally, let us discuss the role of micelles on the $\mathrm{Ag}^{+}$reduction and $\mathrm{Ag}$ nanoparticle formation because PEO-PPO block copolymers form micelles due to the amphiphilic character afforded from hydrophilic PEO block and hydrophobic PPO block. In order to elucidate the role of micelles on the on $\mathrm{Ag}^{+}$reduction and $\mathrm{Ag}$ nanoparticle formation, we tested the $\mathrm{Ag}$ nanoparticle synthesis in aqueous solutions of PEO homopolymer (PEG8000). In fact, Ag nanoparticles were not formed in aqueous solutions of PEO homopolymer in the same experimental condition with PEO-PPO block copolymer system (the result is not shown here). This indicates that the reduction activity of PEO homopolymer for $\mathrm{Ag}^{+}$in aqueous solutions is lower than that of PEO-PPO block copolymers. This is consistent with Au nanoparticle synthesis in PEO homopolymer system. Au nanoparticles were formed at 2 days after reaction initiation [33, 34]. Longenberger and Mill have also reported that Ag nanoparticle formation required 20 days for reaction completion in aqueous solutions of PEO homopolymer [51]. This indicates that the PPO block in the PEO-PPO block copolymer plays an important role for promotion of metal ion reduction. Then, we consider the contribution of micelles to the $\mathrm{Ag}^{+}$ reduction and the resulting Ag nanoparticle formation. However, our findings suggest that the micelles themselves seem to be not related directly to cavity formation, because Pluronic F88 having higher critical micellization concentration $(\mathrm{cmc})$ is most effective for Ag nanoparticle formation in the Pluronic P103, F68, F88, F127 and F108. In the contrast, block copolymer networks (e.g., cyclization and crosslinking) seem to be related to reaction activity (cavity formation). In our previous work reported in reference [34], the kinetic experiments and analysis reveal that concentration of block copolymer participating into $\left[\mathrm{AuCl}_{4}\right]^{-}$reduction at early stage increases with block copolymer concentration for Pluronic F127 and F108 systems while decreases for Pluronic P103 and P105 systems. We believe that the difference is most 
likely due to the balance between cyclization and crosslinking of block copolymers initially formed. Higher cyclization and lower crosslinking induce more effective complexion of polymer with ions while lower cyclization and higher crosslinking induce less complexion of polymer with ions [62]. Degree of polymer crosslinking would increase with increase in block copolymer concentration so that the rate constant would decrease with increase in block copolymer concentration. Longer chain polymers such as Pluronic F88, F127 and F108 should be cyclized so that reduction of $\mathrm{Ag}^{+}$would be enhanced with block copolymer concentration. On the other hand, the lower activity of Pluronic P103 and F68 for $\mathrm{Ag}^{+}$reduction is most likely due to less cyclization of block copolymer because of shorter polymer chains. So, we consider that PEO blocks contribute to metal ion reduction more significantly than PPO blocks at early stage of metal ion reduction because of hydrophobicity of PPO blocks. Instead, PPO blocks induce the adsorption of block copolymers on the metal clusters and/or particles formed, and enhance the metal ion reduction by both PEO and PPO blocks (metal formation) on the surfaces. Furthermore, the adsorption function of PPO blocks improves colloidal stabilization and growth of metal nanoparticles.

\section{Conclusions}

Silver $(\mathrm{Ag})$ nanoparticles were formed directly from aqueous silver nitrate $\left(\mathrm{AgNO}_{3}\right)$ solutions of PEO-PPO block copolymers above $100{ }^{\circ} \mathrm{C}$. This is most likely attributed to the dehydration of water molecules from $\mathrm{Ag}^{+}$by thermal motion of water molecules by high temperature and high vapor pressure. The dehydrated $\mathrm{Ag}^{+}$would interact more significantly with PEO-PPO block copolymers, and hence, $\mathrm{Ag}^{+}$would be reduced by PEO-PPO block copolymers in aqueous solutions. Furthermore, we found that PEO-PPO block copolymers with longer chain (larger molecular weight) are more reactive with $\mathrm{Ag}^{+}$. Also higher 
concentration of PEO-PPO block copolymers enhanced $\mathrm{Ag}^{+}$reduction and $\mathrm{Ag}$ nanoparticle formation. These are most likely due to larger number of looping which act as reaction site afforded from longer chain (larger molecular weight) PEO-PPO block copolymers.

The formation mechanism of Ag nanoparticles in aqueous solutions of PEO-PPO block copolymers presents a range of possibilities for further development. The self-assembled structures afforded by amphiphilic polymers can be exploited as one-, two- and three-dimensional templates for hybrid metal/polymer ordered materials. We are currently exploring the self-formation and -organization of metal nanoparticles on solid particles such as silica particles and polymer particles in solutions. The tunability of block copolymer self-assembly on the solid particles should be an asset to the above. 


\section{References}

[1] P. Barnickel, A. Wokaun, Synthesis of Metal Colloids in Inverse Microemulsions. Mol. Phys., 69(1) (1990) 1-9.

[2] L. M. Liz-Marzan, I. Lado-Tourino, Reduction and Stabilization of Silver Nanoparticles in Ethanol by Nonionic Surfactants. Langmuir, 12(15) (1996) 3585-3589.

[3] M. P. Pileni, Metal Particles Made in Various Colloidal Self-Assemblies: Syntheses and Properties, in: T. Sugimoto (Ed.), Fine Particles: Synthesis, Characterization, and Mechanisms of Growth, Marcel Dekker, New York, 2000, pp. 497-512.

[4] M. Brust, C. J. Kiely, Some recent advances in nanostructure preparation from gold and silver particles: a short topical review. Colloids Surf. A, 202(2-3) (2002) 175-186.

[5] M. C. Daniel, D. Astruc, Gold nanoparticles: Assembly, supramolecular chemistry, quantum-size-related properties, and applications toward biology, catalysis, and nanotechnology. Chem. Rev., 104(1) (2004) 293-346.

[6] C. Burda, X. B. Chen, R. Narayanan, M. A. El-Sayed, Chemistry and properties of nanocrystals of different shapes. Chem. Rev., 105(4) (2005) 1025-1102.

[7] M. Tsuji, M. Hashimoto, Y. Nishizawa, M. Kubokawa, T. Tsuji, Microwave-assisted synthesis of metallic nanostructures in solution. Chemistry-A Europ. J., 11(2) (2005) 440-452.

[8] B. Wiley, Y. G. Sun, B. Mayers, Y. N. Xia, Shape-controlled synthesis of metal nanostructures: The case of silver. Chemistry-A Europ. J., 11(2) (2005) 454-463.

[9] S. Eustis, M. A. El-Sayed, Why gold nanoparticles are more precious than pretty gold: Noble metal surface plasmon resonance and its enhancement of the radiative and nonradiative properties of nanocrystals of different shapes. Chem. Soc. Rev., 35(3) 
(2006) 209-217.

[10] J. Shan, H. Tenhu, Recent advances in polymer protected gold nanoparticles: synthesis, properties and applications. Chem. Commun., (44) (2007) 4580-4598.

[11] Y. J. Xiong, Y. N. Xia, Shape-controlled synthesis of metal nanostructures: The case of palladium. Adv. Mater., 19 (2007) 3385-3391.

[12] J. Park, J. Joo, S. G. Kwon, Y. Jang, T. Hyeon, Synthesis of monodisperse spherical nanocrystals. Angew. Chem. Int. Ed., 46(25) (2007) 4630-4660.

[13] J. Sharma, T. Imae, Recent Advances in Fabrication of Anisotropic Metallic Nanostructures. J. Nanosci. Nanotechnol., 9(1) (2009) 19-40.

[14] J. F. Zhou, J. Ralston, R. Sedev, D. A. Beattie, Functionalized gold nanoparticles: Synthesis, structure and colloid stability. J. Colloid Interface Sci., 331(2) (2009) 251-262.

[15] V. K. Sharma, R. A. Yngard, Y. Lin, Silver nanoparticles: Green synthesis and their antimicrobial activities. Adv. Colloid Interface Sci., 145(1-2) (2009) 83-96.

[16] P. C. Ray, Size and Shape Dependent Second Order Nonlinear Optical Properties of Nanomaterials and Their Application in Biological and Chemical Sensing. Chem. Rev., 110(9) (2010) 5332-5365.

[17] A. Guerrero-Martinez, S. Barbosa, I. Pastoriza-Santos, L. M. Liz-Marzan, Nanostars shine bright for you Colloidal synthesis, properties and applications of branched metallic nanoparticles. Curr. Opin. Colloid Interface Sci., 16(2) (2011) 118-127.

[18] M. B. Cortie, A. M. McDonagh, Synthesis and Optical Properties of Hybrid and Alloy Plasmonic Nanoparticles. Chem. Rev., 111(6) (2011) 3713-3735.

[19] M. Rycenga, C. M. Cobley, J. Zeng, W. Li, C. H. Moran, Q. Zhang, D. Qin, Y. Xia, Controlling the Synthesis and Assembly of Silver Nanostructures for Plasmonic Applications. Chem. Rev., 111(6) (2011) 3669-3712. 
[20] P. Alexandridis, M. Tsianou, Block copolymer-directed metal nanoparticle morphogenesis and organization. Europ. Polym. J., 47(4) (2011) 569-583.

[21] P. Alexandridis, Gold Nanoparticle Synthesis, Morphology Control, and Stabilization Facilitated by Functional Polymers. Chem. Eng. Technol., 34(1) (2011) 15-28.

[22] M. Iwamoto, K. Kuroda, V. Zaporojtchenko, S. Hayashi, F. Faupel, Production of gold nanoparticles-polymer composite by quite simple method. Europ. Phys. J. D, 24(1-3) (2003) 365-367.

[23] T. Ishii, H. Otsuka, K. Kataoka, Y. Nagasaki, Preparation of Functionally PEGylated Gold Nanoparticles with Narrow Distribution through Autoreduction of Auric Cation by a-Biotinyl-PEG-block-[poly(2-(N,N-dimethylamino)ethyl methacrylate)]. Langmuir, $20(3)(2004) 561-564$.

[24] L. Wang, X. Chen, J. Zhan, Z. Sui, J. Zhao, Z. Sun, Controllable Morphology Formation of Gold Nano- and Micro-Plates in Amphiphilic Block Copolymer-Based Liquid Crystalline Phase. Chem. Lett., 33(6) (2004) 720-721.

[25] J. D. S. Newman, G. J. Blanchard, Formation of gold nanoparticles using amine reducing agents. Langmuir, 22(13) (2006) 5882-5887.

[26] J. D. S. Newman, G. J. Blanchard, Formation and encapsulation of gold nanoparticles using a polymeric amine reducing agent. J. Nanoparticle Res., 9(5) (2007) 861-868.

[27] X. P. Sun, X. Jiang, S. J. Dong, E. K. Wang, One-step synthesis and size control of dendrimer-protected gold nanoparticles: A heat-treatment-based strategy. Macromol. Rapid Commun., 24(17) (2003) 1024-1028.

[28] Y. L. Luo, One-step preparation of gold nanoparticles with different size distribution. Mater. Lett., 61(4-5) (2007) 1039-1041.

[29] S. F. Pang, T. Kondo, T. Kawai, Formation of dendrimer-like gold nanoparticle 
assemblies. Chem. Mater., 17(14) (2005) 3636-3641.

[30] P. Khullar, A. Mahal, V. Singh, T. S. Banipal, G. Kaur, M. S. Bakshi, How PEO-PPO-PEO Triblock Polymer Micelles Control the Synthesis of Gold Nanoparticles: Temperature and Hydrophobic Effects. Langmuir, 26(13) (2010) 11363-11371.

[31] P. Khullar, V. Singh, A. Mahal, H. Kaur, V. Singh, T. S. Banipal, G. Kaur, M. S. Bakshi, Tuning the Shape and Size of Gold Nanoparticles with Triblock Polymer Micelle Structure Transitions and Environments. J. Phys. Chem. C, 115(21) (2011) 10442-10454.

[32] F. Dumur, A. Guerlin, E. Dumas, D. Bertin, D. Gigmes, C. R. Mayer, Controlled spontaneous generation of gold nanoparticles assisted by dual reducing and capping agents. Gold Bull., 44(2) (2011) 119-137.

[33] T. Sakai, P. Alexandridis, Single-step synthesis and stabilization of metal nanoparticles in aqueous pluronic block copolymer solutions at ambient temperature. Langmuir, 20(20) (2004) 8426-8430.

[34] T. Sakai, P. Alexandridis, Mechanism of gold metal ion reduction, nanoparticle growth and size control in aqueous amphiphilic block copolymer solutions at ambient conditions. J. Phys. Chem. B, 109(16) (2005) 7766-7777.

[35] T. Sakai, P. Alexandridis, Spontaneous formation of gold nanoparticles in poly(ethylene oxide)-poly(propylene oxide) solutions: Solvent quality and polymer structure effects. Langmuir, 21(17) (2005) 8019-8025.

[36] T. Sakai, P. Alexandridis, Size-and shape-controlled synthesis of colloidal gold through autoreduction of the auric cation by poly(ethylene oxide)-poly(propylene oxide) block copolymers in aqueous solutions at ambient conditions. Nanotechnology, 16(7) (2005) S344-S353.

[37] T. Sakai, P. Alexandridis, Facile preparation of Ag-Au bimetallic nanonetworks. Mater. 
Lett., 60(16) (2006) 1983-1986.

[38] T. Sakai, P. Alexandridis, $A g$ and $A u$ monometallic and bimetallic colloids: Morphogenesis in amphiphilic block copolymer solutions. Chem. Mater., 18(10) (2006) 2577-2583.

[39] T. Sakai, P. Alexandridis, High-yield synthesis of gold microplates using amphiphilic block copolymers: Are lyotropic liquid crystals required? Macromol. Symp., 289(1) (2010) 18-24.

[40] T. Sakai, M. Ishigaki, T. Okada, S. Mishima, A Facile Route of Gold Nanoparticle Synthesis and Surface Modification Using Amino-Terminated Poly(ethylene oxide)-Poly(propylene oxide) Block Copolymers. J. Nanosci. Nanotechnol., 10(2) (2010) 919-926.

[41] T. Sakai, M. Ishigaki, T. Okada, S. Mishima, Multi-shaped Gold Nanoparticles Synthesized Using an Amino-terminated Poly(ethylene oxide)-Poly(propylene oxide) Block Copolymer in Aqueous Solutions. Chem. Lett., 40(5) (2011) 501-503.

[42] T. Sakai, Y. Horiuchi, P. Alexandridis, T. Okada, S. Mishima, Block copolymer-mediated synthesis of gold nanoparticles in aqueous solutions: Segment effect on gold ion reduction, stabilization, and particle morphology. J. Colloid Interface Sci., 394 (2013) 124-131.

[43] L. Z. Zhang, J. C. Yu, H. Y. Yip, Q. Li, K. W. Kwong, A. W. Xu, P. K. Wong, Ambient light reduction strategy to synthesize silver nanoparticles and silver-coated $\mathrm{TiO}_{2}$ with enhanced photocatalytic and bactericidal activities. Langmuir, 19(24) (2003) 10372-10380.

[44] A. K. M. M. Islam, M. Mukherjee, Effect of temperature in synthesis of silver nanoparticles in triblock copolymer micellar solution. J. Exp. Nanosci., 6(6) (2011) 
596-611.

[45] A. K. M. M. Islam, S. Mukherjee, S. Nannarone, M. Mukherjee, Morphology and chemical properties of silver-triblock copolymer nanocomposite thin films. Mater. Chem. Phys., 140(1) (2013) 284-293.

[46] L. Y. Wang, X. Chen, J. K. Zhao, Z. M. Sui, W. C. Zhuang, L. M. Xu, C. J. Yang, Preparation of silver nanoparticles templated from amphiphilic block copolymer-based hexagonal liquid crystals. Colloids Surf. A, 257-58 (2005) 231-235.

[47] T. I. Abdullin, O. V. Bondar, Y. G. Shtyrlin, M. Kahraman, M. Culha, Pluronic Block Copolymer-Mediated Interactions of Organic Compounds with Noble Metal Nanoparticles for SERS Analysis. Langmuir, 26(7) (2010) 5153-5159.

[48] D. G. Angelescu, M. Vasilescu, R. Somoghi, D. Donescu, V. S. Teodorescu, Kinetics and optical properties of the silver nanoparticles in aqueous L64 block copolymer solutions. Colloids Surf. A, 366(1-3) (2010) 155-162.

[49] B. Marta, E. Jakab, M. Potara, T. Simon, F. Imre-Lucaci, L. Barbu-Tudoran, O. Popescu, S. Astilean, Pluronic-coated silver nanoprisms: Synthesis, characterization and their antibacterial activity. Colloids Surf. A, 441 (2014) 77-83.

[50] S. Link, M. A. El-Sayed, Spectral Properties and Relaxation Dynamics of Surface Plasmon Electronic Oscillations in Gold and Silver Nanodots and Nanorods. J. Phys. Chem. B, 103(40) (1999) 8410-8426.

[51] L. Longenberger, G. Mills, Formation of Metal Particles in Aqueous Solutions by Reactions of Metal Complexes with Polymers. J. Phys. Chem., 99(2) (1995) 475-478.

[52] D. H. Chen, Y. W. Huang, Spontaneous Formation of Ag Nanoparticles in Dimethylacetamide Solution of Poly(ethylene glycol). J. Colloid Interface Sci., 255(2) (2002) 299-302. 
[53] K.-J. Liu, Nuclear Magnetic Resonance Studies of Polymer Solutions. V. Cooperative Effects in the Ion-Dipole Interaction between Potassium Iodide and Poly(ethylene oxide). Macromolecules, 1(4) (1968) 308-311.

[54] S. Yanagida, K. Takahashi, M. Okahara, Metal-Ion Complexation of Noncyclic Polyoxyethylene Derivatives. I. Solvent Extraction of Alkali and Alkaline Earth Metal Thiocyanates and Iodides. Bull. Chem. Soc. Jpn., 50(6) (1977) 1386-1390.

[55] A. Warshawsky, R. Kalir, A. Deshe, H. Berkovitz, A. Patchornik, Polymeric Pseudocrown Ethers. 1. Synthesis and Complexation with Transition Metal Anions. J. Am. Chem. Soc., 101(15) (1979) 4249-4258.

[56] B. J. Elliott, A. B. Scranton, J. H. Cameron, C. N. Bowman, Characterization and Polymerization of Metal Complexes of Poly(ethylene glycol) Diacrylates and the Synthesis of Polymeric Pseudocrown Ethers. Chem. Mater., 12(3) (2000) 633-642.

[57] M. D. Adams, P. W. Wade, R. D. Hancock, Extraction of Aurocyanide Ion-Pairs by Polyoxyethylene Extractants. Talanta, 37(9) (1990) 875-883.

[58] A. M. Mathur, A. B. Scranton, Synthesis and Ion-Binding Properties of Polymeric Pseudocrown Ethers: A Molecular Dynamics Study. Sep. Sci. Technol., 30(7-9) (1995) 1071-1086.

[59] Y. Sakai, K. Ono, T. Hidaka, M. Takagi, R. W. Cattrall, Extraction of Alkali Metal Ions and Tetraalkylammonium Ions with Ionic Surfactants Containing a Polyoxyethylene Chain. Bull. Chem. Soc. Jpn., 73(5) (2000) 1165-1169.

[60] K. Yokota, M. Matsumura, K. Yamaguchi, Y. Takada, Synthesis of Polymers with Benzo-19-crown-6 Units via Cylcopolymerization of Divinyl Ethers. Makromol. Chem. Rapid Commun., 4(11) (1983) 721-724.

[61] K. Ono, H. Honda, Proton NMR Chemical Shift Induced by Ionic Association on a 
Poly(ethylene oxide) Chain. Macromolecules, 25(23) (1992) 6368-6369.

[62] B. J. Elliott, W. B. Willis, C. N. Bowman, Polymerization Kinetics of Pseudocrown Ether Network Formation for Facilitated Transport Membranes. Macromolecules, 32(10) (1999) 3201-3208. 
Table 1. Properties of the PEO-PPO block copolymers $\left(\mathrm{EO}_{x} \mathrm{PO}_{y} \mathrm{EO}\right)_{x}$ and PEO homopolymer $\left(\mathrm{EO}_{x}\right)$ used in this study [34]

\begin{tabular}{ccccccc}
\hline Pluronic & $\begin{array}{c}\text { Molecular } \\
\text { weight }\end{array}$ & $\begin{array}{c}\text { PEO } \\
\text { wt\% }\end{array}$ & $\begin{array}{c}\text { PPO block } \\
\text { mol. weight }\end{array}$ & $\begin{array}{c}\text { PEO block } \\
\text { mol. weight }\end{array}$ & $\begin{array}{c}\text { cmc (mM) } \\
\left(\mathbf{2 5}{ }^{\circ} \mathbf{C}\right)\end{array}$ & $\begin{array}{c}\text { Nominal } \\
\text { formula }\end{array}$ \\
\hline P103 & 4950 & 30 & 3465 & 1485 & 0.141 & $\mathrm{EO}_{17} \mathrm{PO}_{60} \mathrm{EO}_{17}$ \\
\hline F68 & 8400 & 80 & 1680 & 6720 & 320.5 & $\mathrm{EO}_{76} \mathrm{PO}_{29} \mathrm{EO}_{76}$ \\
\hline F88 & 11400 & 80 & 2280 & 9120 & 11.51 & $\mathrm{EO}_{103} \mathrm{PO}_{39} \mathrm{EO}_{103}$ \\
\hline F127 & 12600 & 70 & 3780 & 8820 & 0.555 & $\mathrm{EO}_{100} \mathrm{PO}_{65} \mathrm{EO}_{100}$ \\
\hline F108 & 14600 & 80 & 2920 & 11680 & 3.082 & $\mathrm{EO}_{132} \mathrm{PO}_{50} \mathrm{EO}_{132}$ \\
\hline PEO & 8000 & 100 & 0 & 8000 & - & $\mathrm{EO}_{181}$ \\
\hline
\end{tabular}

cmc: critical micellization concentration 


\section{Figure captions}

Figure 1. (Upper panel) Absorption spectra recorded at $24 \mathrm{~h}$ after mixing an aqueous $\mathrm{AgNO}_{3}$ solution $(0.2 \mathrm{mM})$ with aqueous Pluronic F88 solution (10 wt $\%)$ at different reaction temperatures: $-1,5,25,40,6080,100,120$ and $140{ }^{\circ} \mathrm{C}$. (Bottom panel) Absorbance centered at $\sim 410 \mathrm{~nm}$ originating from SPR of silver nanoparticles recorded at $24 \mathrm{~h}$ after mixing an aqueous $\mathrm{AgNO}_{3}$ solution $(0.2 \mathrm{mM})$ with an aqueous PEO-PPO block copolymer solution (10 wt\%) : (口) Pluronic P103, $(\triangle)$ Pluronic F68, $(\bullet)$ Pluronic F88, (A) Pluronic F127 and $(\diamond)$ Pluronic F108, plotted as a function of reaction temperature. Also shown are (०) absorbances at $410 \mathrm{~nm}$ of aqueous $\mathrm{AgNO}_{3}$ solution left standing at 5, 25, 40, $6080,100,120$ and $140{ }^{\circ} \mathrm{C}$ for $24 \mathrm{~h}$, as control experiments.

Figure 2. (Upper panel) Absorption spectra recorded at $24 \mathrm{~h}$ after mixing an aqueous $\mathrm{AgNO}_{3}$ solution $(0.2 \mathrm{mM})$ with aqueous PEO-PPO block copolymers solution $(10 \mathrm{wt} \%)$ at $120{ }^{\circ} \mathrm{C}$. (Bottom panel) Absorbance centered at $\sim 410 \mathrm{~nm}$ originating from SPR of Ag nanoparticles recorded at $24 \mathrm{~h}$ after mixing an aqueous $\mathrm{AgNO}_{3}$ solution $(0.2 \mathrm{mM})$ with an aqueous PEO-PPO block copolymer solution $(10 \mathrm{wt} \%)$ at $(\circ) 100{ }^{\circ} \mathrm{C},(\bullet) 120{ }^{\circ} \mathrm{C}$ and $(\square) 140{ }^{\circ} \mathrm{C}$ plotted as a function of molecular weight of PEO-PPO block copolymer.

Figure 3. TEM images of Ag nanoparticles synthesized in 10 wt\% PEO-PPO block copolymer aqueous solutions at $120{ }^{\circ} \mathrm{C}$ : (top images) Pluronic F88, (middle images) Pluronic F127 and (bottom images) Pluronic F108.

Figure 4. X-ray diffraction patterns of Ag nanoparticles synthesized in $10 \mathrm{wt} \%$ PEO-PPO 
block copolymer aqueous solutions at $120{ }^{\circ} \mathrm{C}$ : (top panel) Pluronic F88, (middle panel) Pluronic F127 and (bottom panel) Pluronic F108.

Figure 5. (Upper panel) Absorption spectra recorded at $24 \mathrm{~h}$ after mixing an aqueous $\mathrm{AgNO}_{3}$ solution $(0.2 \mathrm{mM})$ with aqueous Pluronic F88 solution with different concentrations: 0, 1.0, 5.0, 10, 15 and $20 \mathrm{wt} \%$ at $120{ }^{\circ} \mathrm{C}$. (Bottom panel) Absorbance centered at $\sim 410 \mathrm{~nm}$ originating from SPR of Ag nanoparticles recorded at $24 \mathrm{~h}$ after mixing an aqueous $\mathrm{AgNO}_{3}$ solution $(0.2$ $\mathrm{mM}$ ) with an aqueous PEO-PPO block copolymer solution at $120{ }^{\circ} \mathrm{C}$ : $(\square)$ Pluronic P103, $(\triangle)$

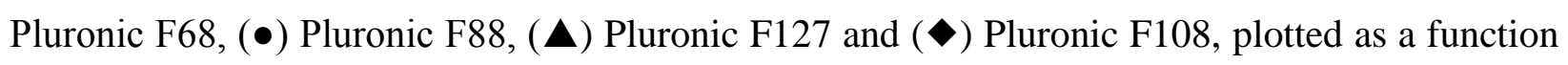
of block copolymer concentration.

Figure 6. Schematic illustration of $\mathrm{Ag}$ nanoparticle formation from $\mathrm{Ag}^{+}$in an aqueous PEO-PPO block copolymer solution above $100{ }^{\circ} \mathrm{C}$. 
Figure 1. Sakai et al.
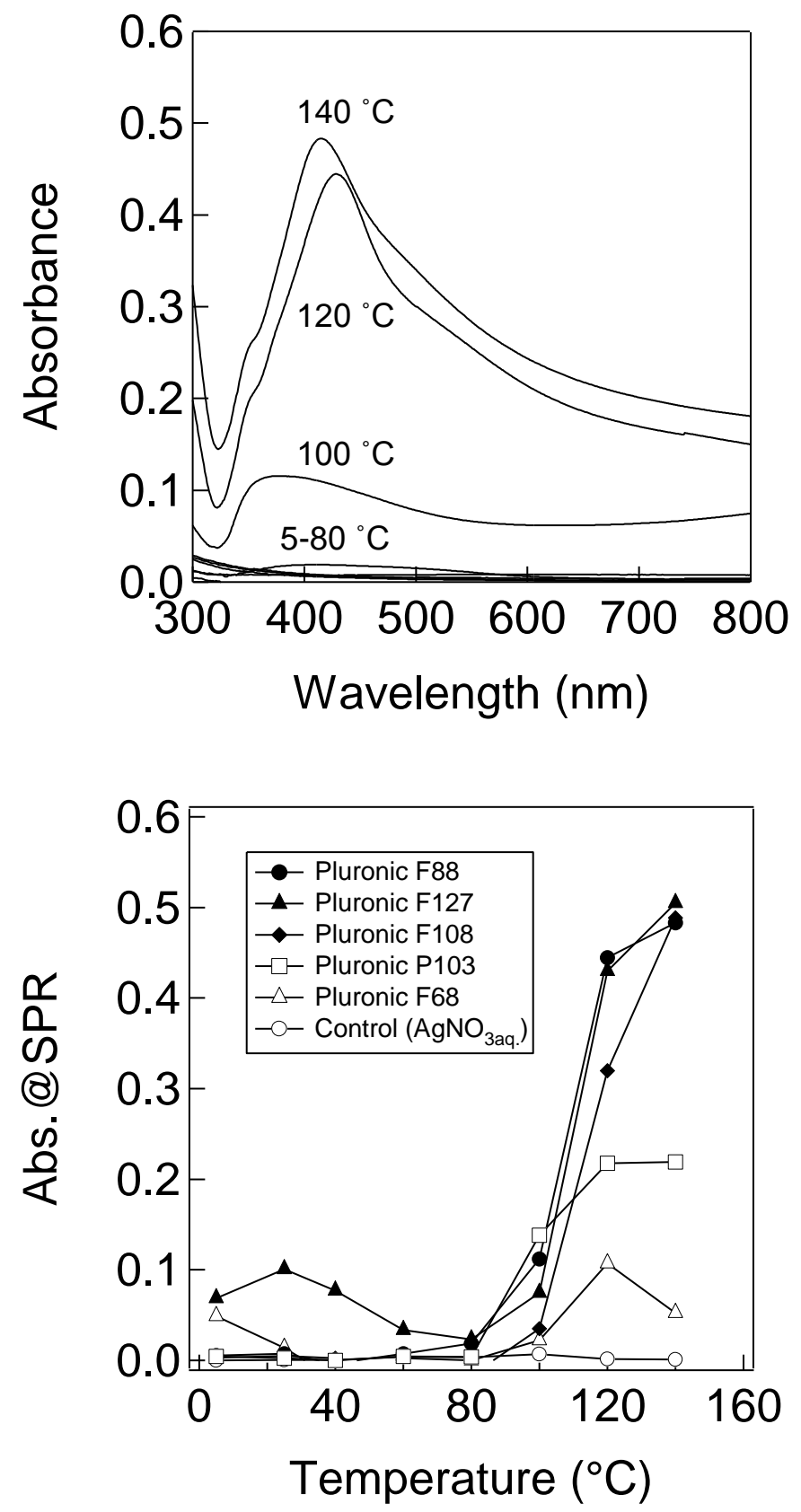
Figure 2. Sakai et al.
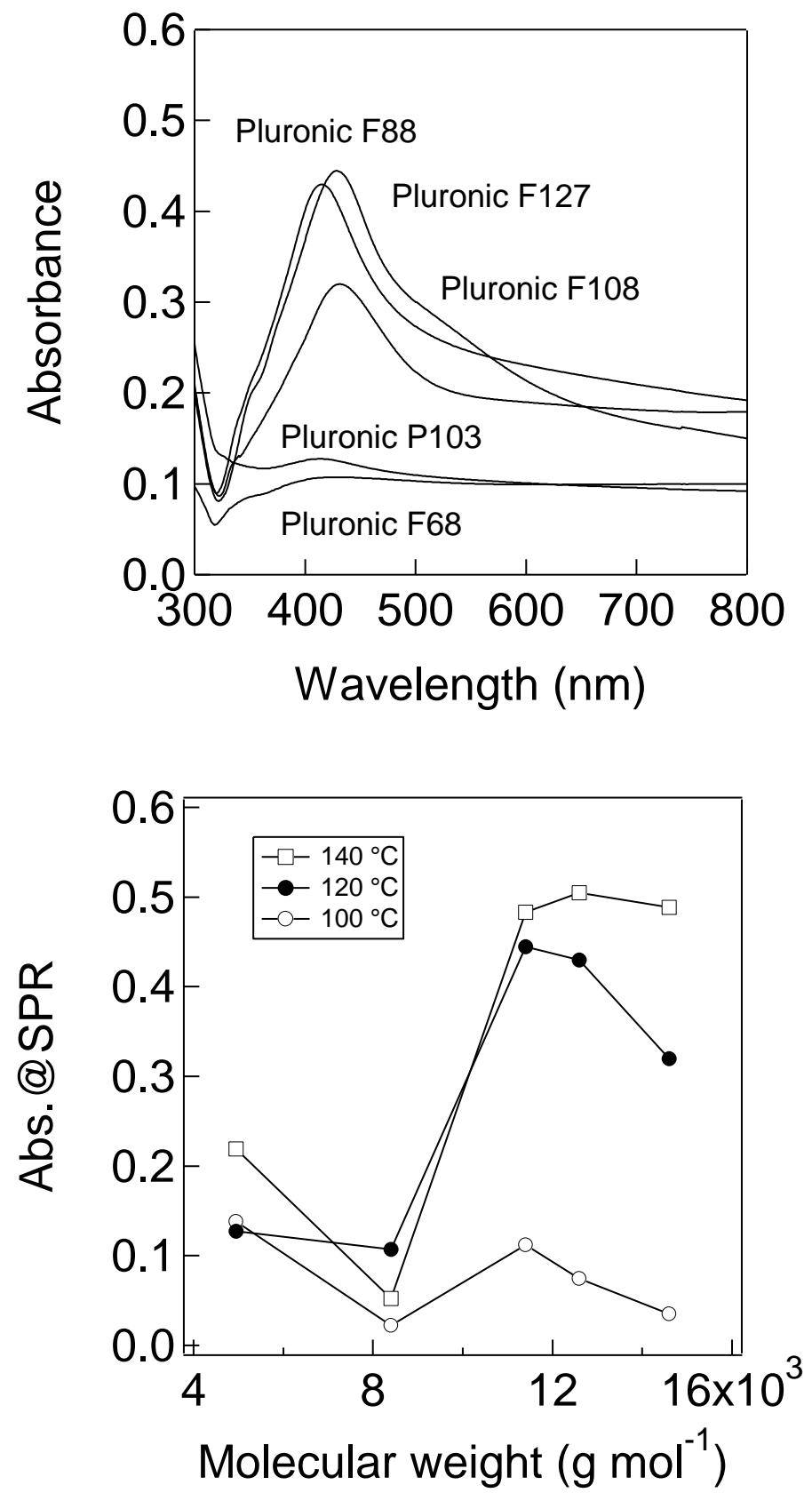
Figure 3. Sakai et al.

10 wt\% Pluronic F88 aq. at $120{ }^{\circ} \mathrm{C}$

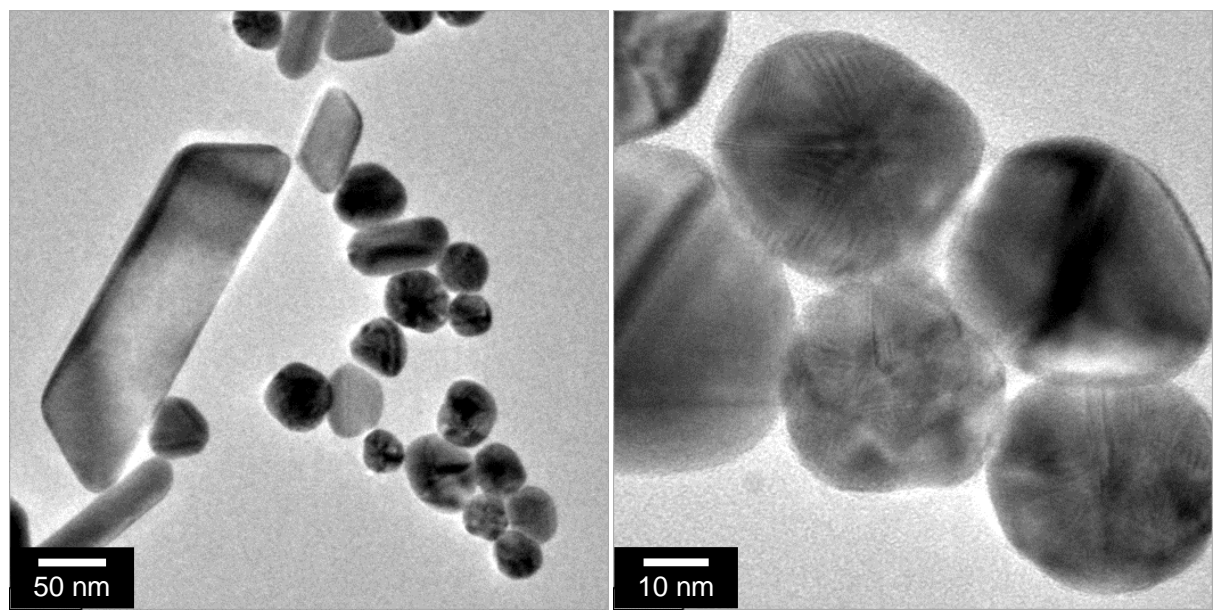

10 wt\% Pluronic $\mathrm{F} 127_{\text {aq }}$ at $120^{\circ} \mathrm{C}$

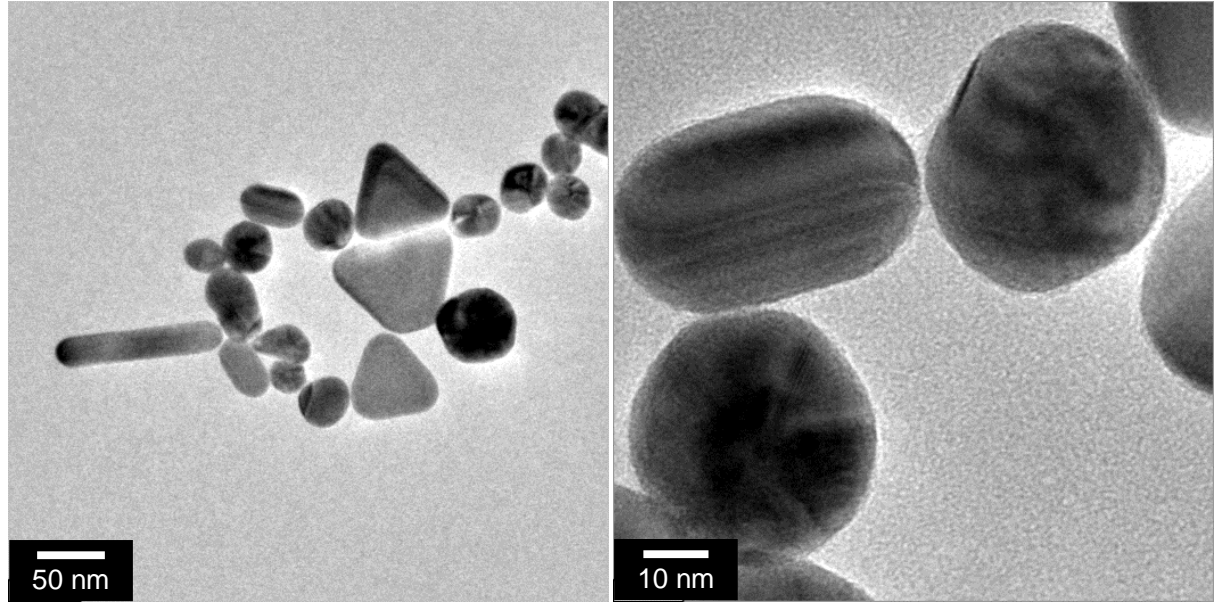

$10 \mathrm{wt} \%$ Pluronic F108 aq. at $120^{\circ} \mathrm{C}$
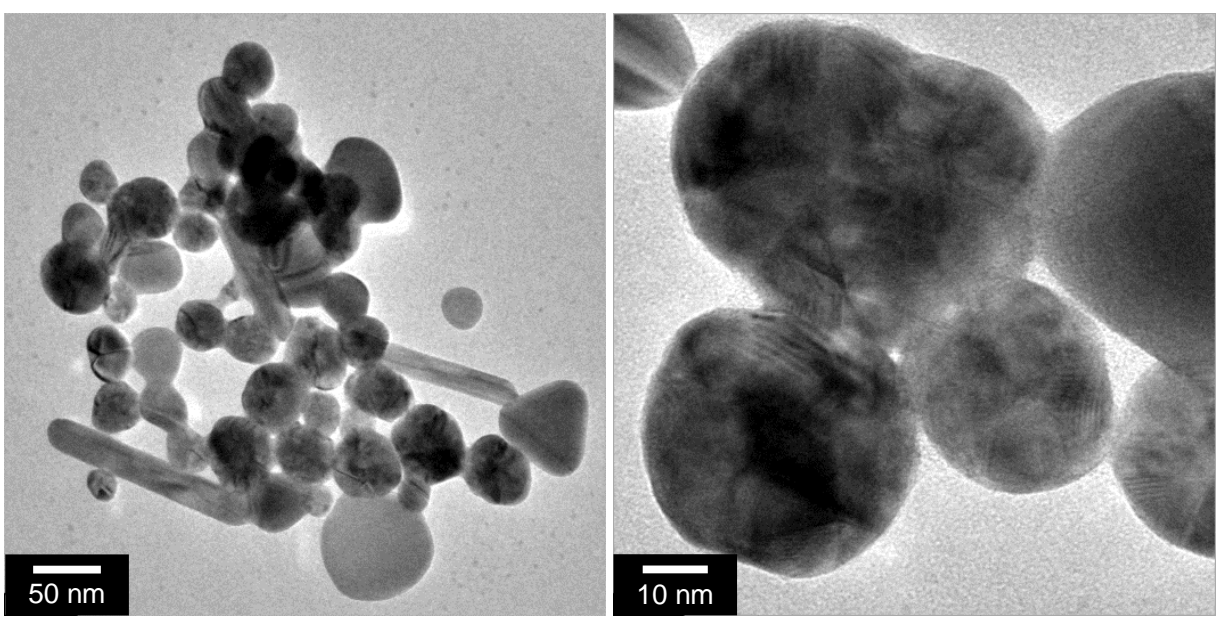
Figure 4. Sakai et al.

$10 \mathrm{wt} \%$ Pluronic F88 aq. at $120{ }^{\circ} \mathrm{C}$
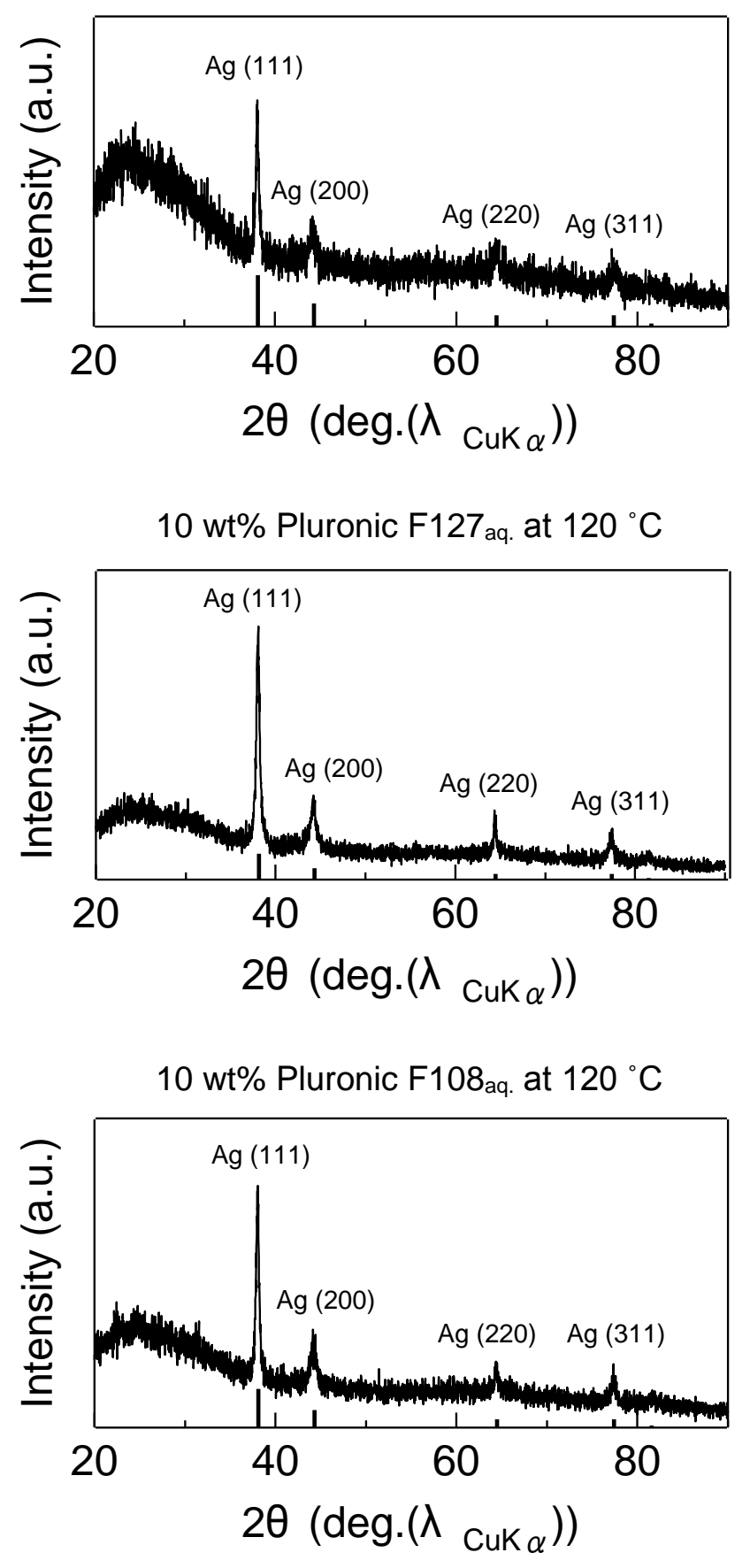
Figure 5. Sakai et al.
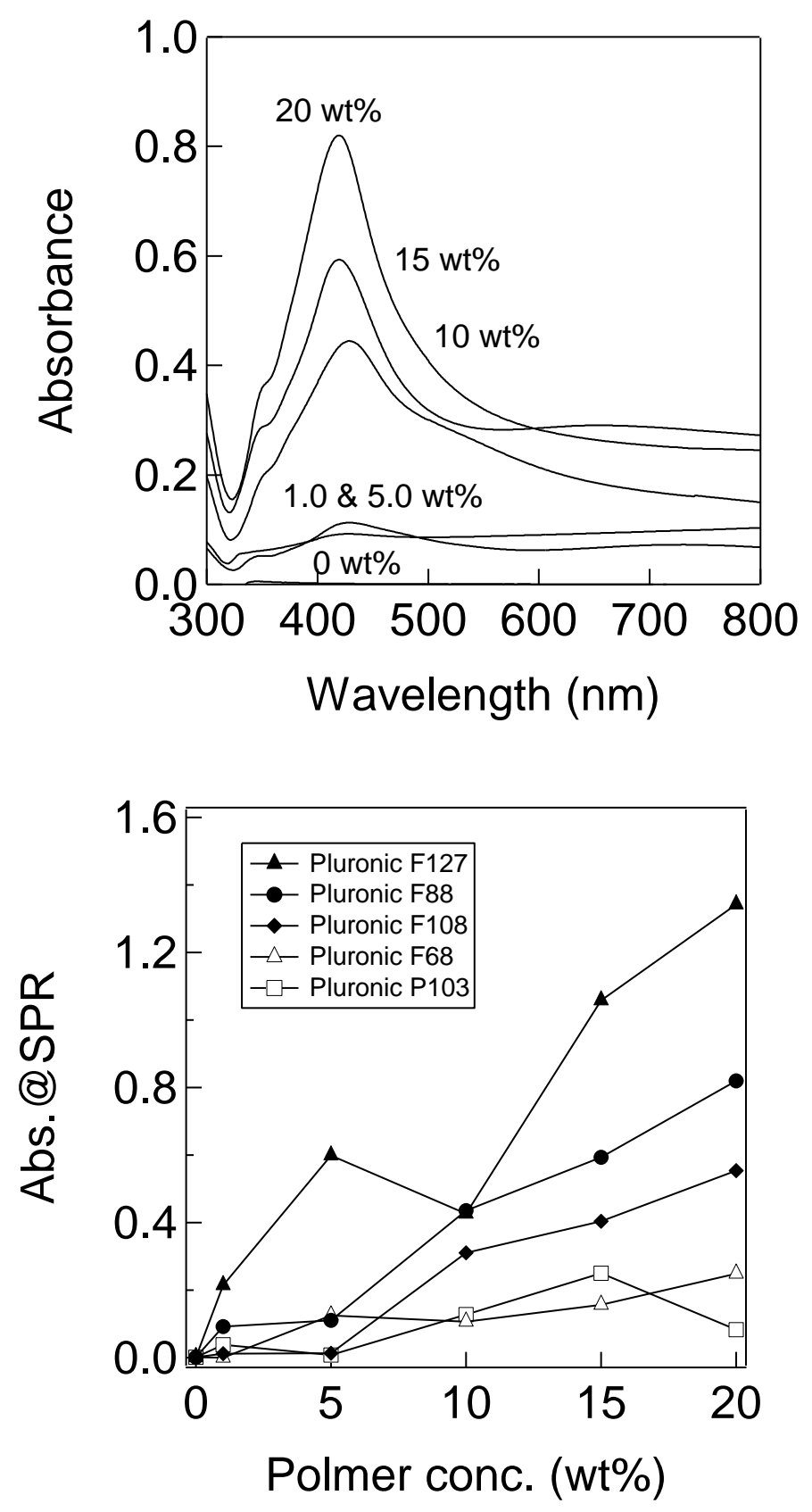
Figure 6. Sakai et al.

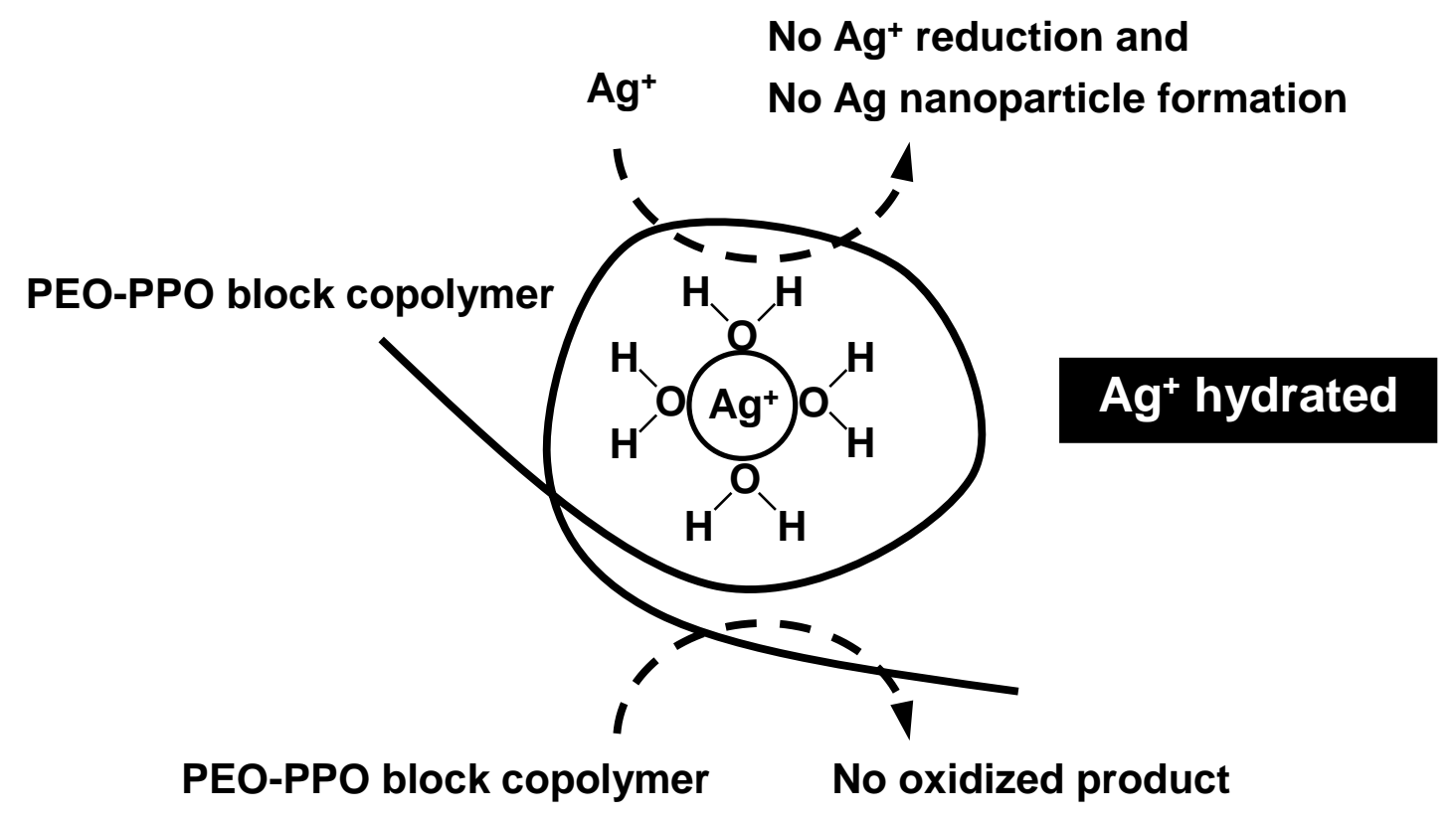

\section{$>100^{\circ} \mathrm{C}$}

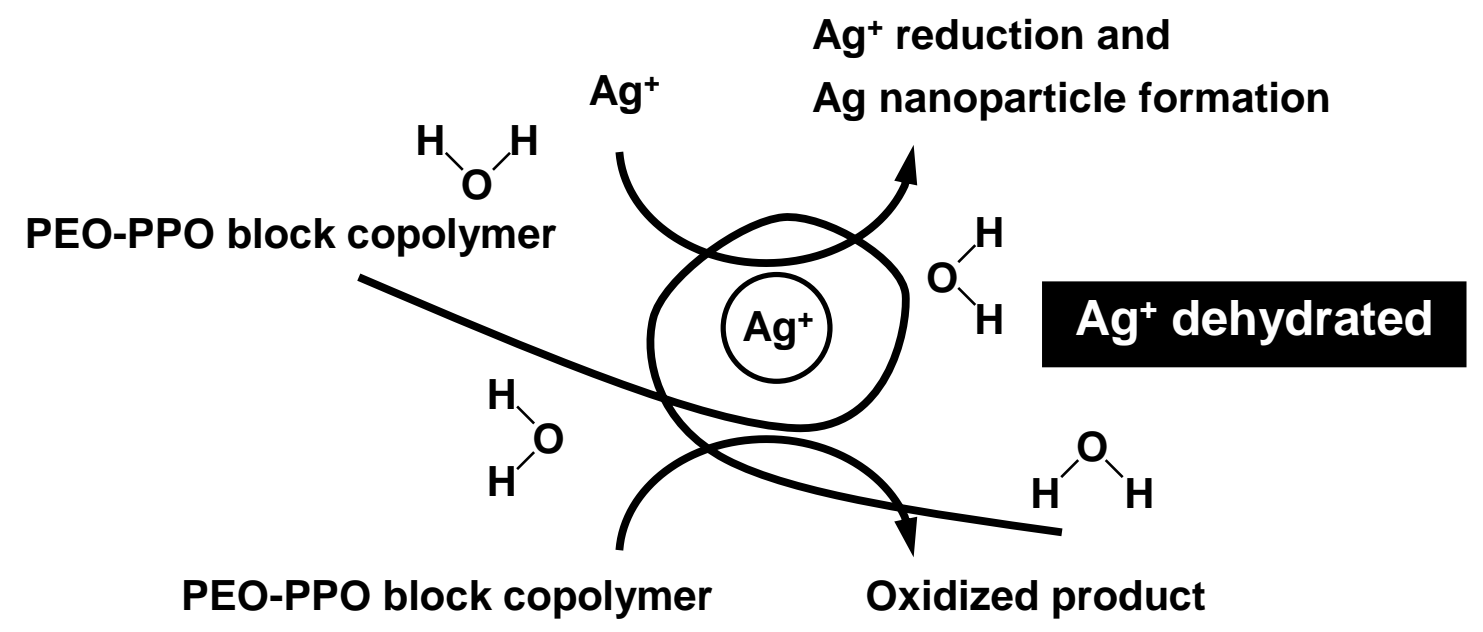

